\title{
PELATIHAN PRODUKSI JAHE INSTAN IBU-IBU DI RT. 12 - RW. 03 KELURAHAN MULYOREJO KECAMATAN SUKUN KOTA MALANG
}

\author{
Koesmarijanto, S.T, M.T ${ }^{1}$; Ir. Hudiono, MT ${ }^{2}$; Ir. Nugroho Suharto ${ }^{3}$, MT; Aad Hariyadi, SST, MT ${ }^{4}$ \\ ${ }_{1,2,3,4}$ Prodi Teknik Telekomunkasi, Jurusan Teknik Elektro, Politeknik Negeri Malang \\ koesmarijanto@mail.polinema.ac.id
}

\begin{abstract}
Ginger is a type of spice that is widely used traditionally as a medicine. The content of essential oils and oleoresin in ginger has antibacterial activity. Today many foods and drinks are offered as supplement products that can improve body health if consumed. Health drinks are drinks that contain elements of nutrients or non-nutrients and if consumed can have a positive influence on body health. Health drinks as one of the products that are well known to the public, are often found on the market with various brands and forms, such as liquid, instant powder or tablets.

This activity aims to provide alternative skills for PKK RT mothers. 12 - RW. 03 Mulyorejo Village, Sukun District, Malang City, can develop entrepreneurship in products made from ginger.

Each participant of this activity knows how to use ginger for making instant drinks and brings the results of training in the form of instant ginger. The community service activities that have been carried out have provided many benefits, especially adding broader insights in understanding the concept of food business development, especially in the use of ginger and applying the theory of extraction and crystallization in the manufacture of instant drinks. This community service activity can be used as a new opportunity to develop entrepreneurship..
\end{abstract}

Kata kunci: essential oil, instant ginger, entrepreneur

\section{PENDAHULUAN}

\subsection{Latar Belakang}

Mobilitas masyarakat yang semakin tinggi memerlukan kondisi kesehatan yang optimal. Kondisi kesehatan tubuh tentunya tidak bisa lepas dari konsumsi makanan dan minuman yang sehat. Banyaknya penyakit yang ditimbulkan karena cara mengkonsumsi makanan dan minuman yang salah atau keamanan makanan dan minuman yang tidak terjaga menyebabkan masyarakat cenderung bersikap hatihati.

Saat ini banyak minuman yang ditawarkan sebagai produk suplemen yang dapat meningkatkan kesehatan tubuh jika dikonsumsi. Minuman kesehatan merupakan minuman yang mengandung unsur-unsur zat gizi atau non zat gizi dan jika dikonsumsi dapat memberikan pengaruh posistif terhadap kesehatan tubuh. Minuman kesehatan sebagai salah satu produk yang sudah dikenal masyarakat, banyak dijumpai di pasaran dengan berbagai merek dan bentuk, seperti dalam bentuk cair, serbuk instan atau tablet. Kecenderungan masyarakat saat ini adalah lebih suka menggunakan produk yang kemasan dan penyajiannya lebih praktis dan cepat, karena tidak perlu embutuhkan banyak waktu dalam mempersiapkannya. Salah satu contoh minuman kesehatan yang dapat dijumpai adalah minuman instan ekstrak jahe, dimana produk tersebut umumnya dibuat dengan mengambil sari dari rimpang jahe kemudian dilakukan pengolahan lanjut. Kebanyakan produk tersebut dijumpai dalam bentuk serbuk, di samping ada beberapa yang dibuat dalam bentuk tabled maupun cair.

Ibu-ibu PKK RT. 12 - RW. 03 Kelurahan Mulyorejo Kecamatan Sukun Kota Malang memiliki agenda rutin mengadakan pertemuan yang dilaksanakan setiap bulan. Anggotanya adalah ibu-ibu warga setempat yang pada umumnya adalah ibu-ibu rumah tangga yang hampir seluruhnya tidak memiliki pekerjaan tetap dan masih mengandalkan penghasilan dari suami yang pekerjaannya tidak tetap.

Setiap rumah di lingkungan RT yang memiliki lahan digunakan menanam tanaman Toga untuk kebutuhan dapur juga bisa digunakan budidaya tanaman lain. Disamping untuk kebutuhan di dapur, diharapkan ibu-ibu di RT. 12 - RW. 03 mulai mananam dalam skala kecil, sehingga hasilnya bisa digunakan untuk kebutuhan pribadi dan juga bisa untuk usaha.

Hasil diskusi dan wawancara dengan anggota PKK RT.12 - RW.03 Kelurahan Mulyorejo Kecamatan Sukun Kota Malang, belum pernah pendapatkan penyuluhan tentang cara pembuatan jahe instan dari pihak manapun. Kondisi warga RT. 12 - RW. 03 Kelurahan Mulyorejo Kecamatan Sukun Kota Malang, memungkinkan ibu-ibu warga setempat bisa berkoordinasi untuk membuat suatu kegiatan yang dapat menghasilkan nilai tambah untuk menambah penghasilan atau untuk kebutuhan keluarga.

\subsection{Rumusan Masalah}

1. Bagaimana meningkatkan pengetahuan dan ketrampilan cara membuat jahe instan.

2. Bagaimana mengolah jahe dalam bentuk kristal yang bisa disajikan secara cepat.

3. Bagaimana mengemas jahe dalam bentuk kristal (instan) agar layak dipasarkan.

4. Bagaimana meningkatkan pengetahuan berwirausaha ibu-ibu PKK RT.12 - RW.03 Kelurahan Mulyorejo Kecamatan Sukun Kota Malang.

\subsection{Tujuan Kegiatan}

Tujuan dilasanakan pengabdian kepada masyarakat adalah memberikan pengetahuan, 
ketrampilan, dan pelatihan tentang jahe menjadi kristal (instan) serta wirausaha RT. 12 - RW. 03 Kelurahan Mulyorejo Kecamatan Sukun Kota Malang.

\subsection{Manfaat Kegiatan}

Penelitian diharapkan dapat memberikan kontribusi kepada masyarakat adalah ibu rumah tangga dapat memanfaatkan taraf ekonomi dengan melakukan penghematan cara mencukupi kebutuhan keluarga dengan yang ada di sekitar dan membantu penghasilan keluarga dengan kewirausahaan

\section{LANDASAN TEORI}

\subsection{Jahe}

Jahe (Zingiber officinale), adalah tanaman rimpang yang sangat populer sebagai rempah-rempah dan bahan obat. Rimpangnya berbentuk jemari yang menggembung di ruas-ruas tengah. Rasa dominan pedas disebabkan senyawa keton bernama zingeron. Jahe termasuk suku Zingiberaceae (temu-temuan). Nama ilmiah jahe diberikan oleh William Roxburgh dari kata Yunani zingiberi, dari Bahasa Sansekerta, singaberi (Nuruljanah, Tantri).

Berdasarkan ukuran dan warna rimpangnya, jahe dapat dibedakan menjadi 3 (tiga) varietas, yaitu jahe besar (jahe gajah), jahe kecil (jahe emprit), dan jahe merah (jahe sunti). Jahe merah dan jahe kecil banyak dimanfaatkan sebagai bahan obat-obatan. Sedangkan jahe besar dimanfaatkan sebagai bumbu masak (Matondang, 2005). Secara tradisional ekstrak jahe digunakan antara lain sebagai obat sakit kepala, obat batuk, masuk angin, untuk mengobati gangguan pada saluran pencernaan, stimulansia, diuretik, rematik, menghilangkan rasa sakit, obat anti-mual dan mabuk perjalanan, karminatif (mengeluarkan gas dari perut) dan sebagai obat luar untuk mengobati gatal digigit serangga, keseleo, bengkak, serta memar (Shukla, 2007).

\subsection{Klasifikasi Tanaman Jahe}

Jahe termasuk tanaman yang berasal dari daerah Asia Tropik, yang tersebar di berbagai wilayah dari India sampai Cina. Sejak zaman Kong Hu (551479 SM), jahe sudah dibudidayakan di India, dan diekspor ke Cina. Di kawasan Asia, tanaman jahe tersebar hampir di seluruh daerah tropika basah. Saat ini, tanaman jahe dibudidayakan di berbagai daerah di Indonesia, antara lain adalah Sumatera Utara, Bengkulu, Jawa Barat, Jawa Tengah, dan Jawa Timur (Sidqa Hanief. 2013:5).

$\begin{array}{cl}\text { Klasifikasi Ilmiah } & \\ \cdot \text { Divisi } & \text { : Spermatophyta. } \\ \cdot \text { Sub-divisi } & \text { : Angiospermae. } \\ \cdot \text { Kelas } & : \text { Monocotyledoneae. } \\ \text { - Ordo } & : \text { Zingiberales. } \\ \text { - Famili } & : \text { Zingiberaceae. } \\ \text { - Genus } & : \text { Zingiber. } \\ \text { - Species } & : \text { Zingiber officinale }\end{array}$

\subsection{Kandungan Kimiawi dan Manfaat Jahe}

Kandungan kimiawi yang terdapat pada rimpang jahe menentukan aroma dan kepedasan jahe. Terdapat beberapa faktor yang mempengaruhi komposisi kimia rimpang jahe, antara lain jenis jahe, tanah dimana jahe ditanam, umur jahe saat dipanen, pengolahan rimpang jahe, dan ekosistem tempat jahe berada (Rukmana, Rahmat. 2000). Rimpang jahe dapat digunakan sebagai bumbu masak, pemberi aroma dan rasa pada makanan seperti roti, kue, biskuit, kembang gula dan berbagai minuman. Jahe juga dapat digunakan pada industri obat, minyak wangi, industri jamu tradisional, diolah menjadi asinan jahe, dibuat acar, lalap, bandrek, sekoteng dan sirup. Adapun manfaat secara pharmakologi antara lain sebagai karminatif (peluruh kentut), anti muntah, pereda kejang, anti pengerasan pembuluh darah, peluruh keringat, anti inflamasi, anti mikroba dan parasit, anti piretik, anti rematik, serta merangsang pengeluaran getah lambung dan getah empedu.

Jahe merupakan tanaman tahunan, berbatang semu dengan tinggi antara $30-75 \mathrm{~cm}$. Berdaun sempit memanjang menyerupai pita, dengan panjang $15-23$ $\mathrm{cm}$, lebar lebih kurang $2,5 \mathrm{~cm}$, tersusun teratur dua baris berseling. Tanaman jahe hidup merumpun, beranak-pinak, menghasilkan rimpang, dan berbunga. Bungan berupa malai yang tersembul pada permukaan tanah, berbentuk tongkat atau bulat telur, dengan panjang lebih kurang $25 \mathrm{~cm}$. Mahkota bunga berbentuk tabung, dengan helaian agak sempit, tajam, berwarna kuning kehijauan. Rimpang jahe memiliki bentuk yang bervariasi, mulai agak pipih sampai bulat panjang, dengan warna putih kekuning-kuningan hingga kuning kemerah-merahan. Di Indonesia, jahe dikenal dengan beberapa nama anatara lain halia, haliya, lea, lia, lahia, jhai,jahi, jhahik, moyuman, beuing, hairale, masin manas, reja, pimedas, jahja, padeh,sipode,sipadas, pege, bahing, ai manas, naije, sedap, sehi, sewe, laie, gore, gisoro, gihori, dan yoyo.

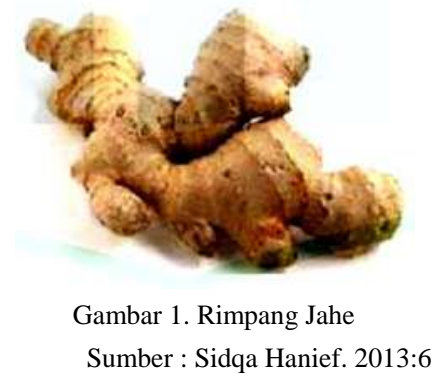

Terdapat tiga jenis jahe berdasarkan ukuran, bentuk, dan warna rimpang, yaitu jahe gajah (Zingiber officinale Roscoe) atau jahe putih, jahe putih kecil (Zingiber officinale Amarum) atau jahe emprit, dan jahe merah (Zingiber officinale Rubrum) atau jahe sunti (Hanief, Sidqa. 2013:6).

\section{METODOLOGI}

Kegiatan ini dilakukan dalam dua materi, materi pertama yaitu memberikan motivasi, dorongan dan inisiatif dalam pengembangan kewirausahaan tentang materi karakteristik tanaman jahe, manfaat tanaman 
jahe untuk kesehatan dan produksi makanan, cara berproduksi yang baik dengan memperhatikan sanitasi higiene, standar mutu dan keamanan pangan. Materi kedua tentang praktik dan bimbingan, peserta melaksanakan praktik pengolahan aneka produk olahan dengan bahan dasar jahe secara mandiri dengan pembimbingan, mulai dari perencanaan produksi, pemilihan bahan baku, pengenalan alat produksi dan pengolahan.

\subsection{Metoda Pelaksanaan}

\section{- Metode Penyediaan Bahan}

Semua bahan yang digunakan untuk pembuatan minuman instan jahe dipilih bahan yang kualitasnya baik, utuh dan tidak ada penyimpangan dalam hal warna bentuk dan kesehatannya. Untuk itulah perlu dilakukan proses seleksi dan triming. Adapun bahan yang diperlukan adalah : Jahe emprit 250 gram Gula pasir 250 gram Air $500 \mathrm{ml}$.

\section{- Metode Penyediaan Alat}

Pastikan semua peralatan yang digunakan dalam keadaan bersih dan higienis. Peralatan yang terbuat dari logam, pilih yang terbuat dari stainless steel. Sedangkan peralatan lainnya sebaiknya berbahan dasar kayu.

\section{- Metoda Penyediaan Alat}

Pastikan semua peralatan yang digunakan dalam keadaan bersih dan higienis. Peralatan yang terbuat dari logam, pilih yang terbuat dari stainless steel. Sedangkan peralatan lainnya sebaiknya berbahan dasar kayu.

\section{- Proses Pembuatan Dasar}

Proses pembuatan jahe instan pada dasarnya dapat dicermati pada diagram proses pembuatan minuman jahe instan sebagai berikut :

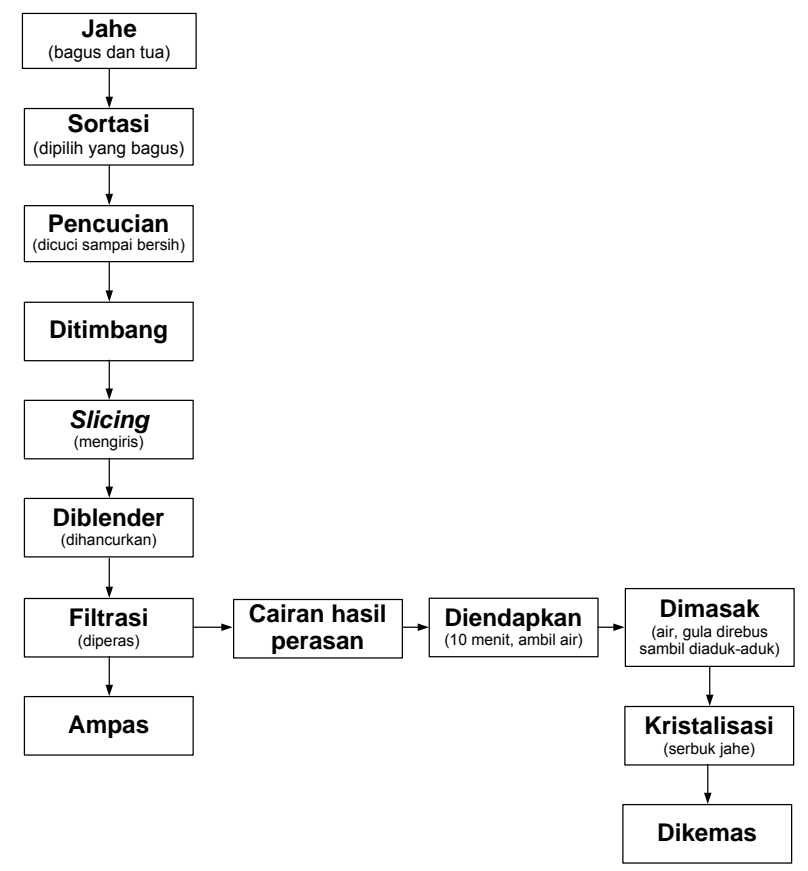

Gambar 1. Diagram Alur Proses Pembuatan Jahe Instan

Sama halnya dengan proses pembuatan instan yang lain, maka diagram proses tersebut diatas dapat dijelaskan bahwa pembuatan dan minuman jahe instan dilakukan 3 tahapan yaitu tahap persiapan, tahap pengolahan, dan tahap finishing.

\subsection{Tahap persiapan}

Tahap persiapan meliputi sortasi, trimming dan sicling. Sortasi atau pemilihan bahan dilakukan untuk memperoleh bahan sesuai persyaratan. Bahan baku rimpang jahe dipilih dari jenis jahe emprit (karena kandungan oleresinnya tinggi) yang sudah cukup tua dan baik keadaannya, tidak mengalami kerusakan. Gula pasir dipilih yang bersih dan kering. Kecuali ada bahan lain seperti penyedap dan pelengkap yaitu cengkeh, sereh, kayu manis, dan akar alang-alang.

Triming digunakan untuk memisahkan bagianbagian yang tidak diperlukan atau dianggap membahayakan. Trimming dilakukan terhadap jahe yang mengupas kulitnya dan terhadap sereh dan akar alang-alang agar bersih dari kotoran. Adapun slicing dilakukan terhadap rimpang jahe yang sudah dicuci dengan mengiris tipis-tipis untuk memperluas permukaan.

\subsection{Tahap pengolahan}

Tahap pengolahan meliputi ekstraksi, perebusan dan kristalisasi. Proses ekstraksi dilakukan untuk memisahkan sari dari bahan jahe. Cara yang digunakan adalah memblender jahe yang diiris tipis dan ditambah sejumlah air, kemudian diperas dan disaring agar sari jahe yng diperoleh bersih dari kotoran. Cara ekstraksi seperti ini disebut ekstraksi mekanis.

Proses perebusan dilakukan dalam wajan, bahanbahan seperti sari jahe, akar alang-alang, sereh kayu manis, dan cengkeh direbus hingga volumenya tinggal separuh dan disaring.

Kristalisasi merupakan proses terpenting untuk memperoleh produk berupa serbuk instan. Kristal dapat terbentuk karena suatu larutan dalam keadaan atau kondisi lewat jenuh (super saturated) karena zat pelaru sudah tidak mampu lagi untuk melarutkan zat terlarutnya atau jumlah zat terlarut sudah melewati kapasitas pelarutnya kondisi ini bisa tercapai apabila pelarutnya berkurang. Untuk mencapai kondisi tersebut, larutan harus direbus terus sambil diadukaduk sehingga terjadi penguapan yang menyebabkan tercapainya kondisi lewat jenuhdan terbentuklah kristalkristal.

Proses pembuatan minuman instan yang berbahan dasar jahe ini terdapat dua prinsip dasar yakni ekstraksi dan kristalisasi. Proses ekstraksi dilakukan terhadap rimpang jahe untuk memperoleh kandungan-kandungan aktifnya berupa sari jahe. Pada dasarnya kristalisasi digunakan untuk memisahkan padatan cairan melalui perpindahan massa dari fase cair ke fase kristal (padat) yang dilakukan dengan penguapan. Sari jahe hasil ekstrasi dicampur dengan gula pasir direbus sampai mendidih dan dilanjutkan sampai tercapai kondisi lewat jenuh (super saturated). Dalam kondisi seperti ini akan tumbuh inti kristal dan terjadilah pertumbuhan kristal selanjutnya.

\subsection{Tahap finishing}


Tahap finishing produk ini dikemas dalam kantong filter celup yang dengan komposisi jahe dan melati sesuai takaran yang telah ditentukan untuk memudahkan konsumen dalam membuat minuman ini. Menjadi produk yang diterima dan dikonsumsi oleh masyarkat.Pada proses finishing, bahan tersebut dikemas dan dirangkai dengan benang yang telah di rekatkan pada label menggunakan alat press. Kemudian kemasan di masukkan ke dalam boks kecil.

\section{HASIL DAN PEMBAHASAN}

\subsection{Hasil}

Hasil pelatihan adalah pengetahuan dan ketrampilan dalam bidang boga terutama dalam pengolahan jahe dengan diolah menjadi berbagai macam produk-produk seperti jahe serbuk (jahe instan), jahe kering dan sirup jahe dengan nilai jual yang lebih tinggi. Berdasarkan materi yang telah disampaikan, maka para peserta sudah dapat membuat produk jahe sesuai dengan prosedur dan materi yang telah disampaikan dan segera akan mewujudkan langkah-langkah untuk mengembangkan kewirausahaan.

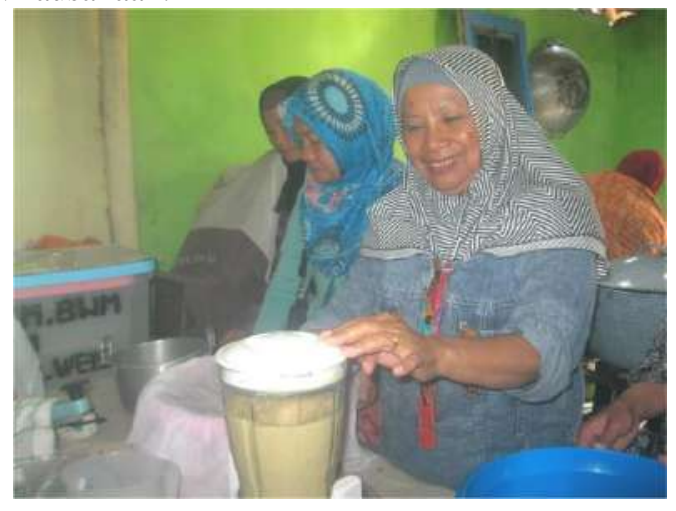

Gambar 2. Pelatihan proses produksi jahe instan

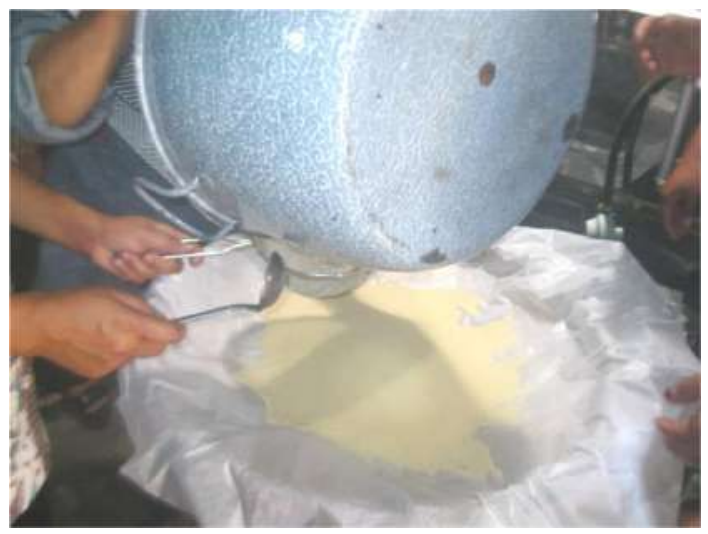

Gambar 3. Hasil pengolahan jahe menjadi serbuk

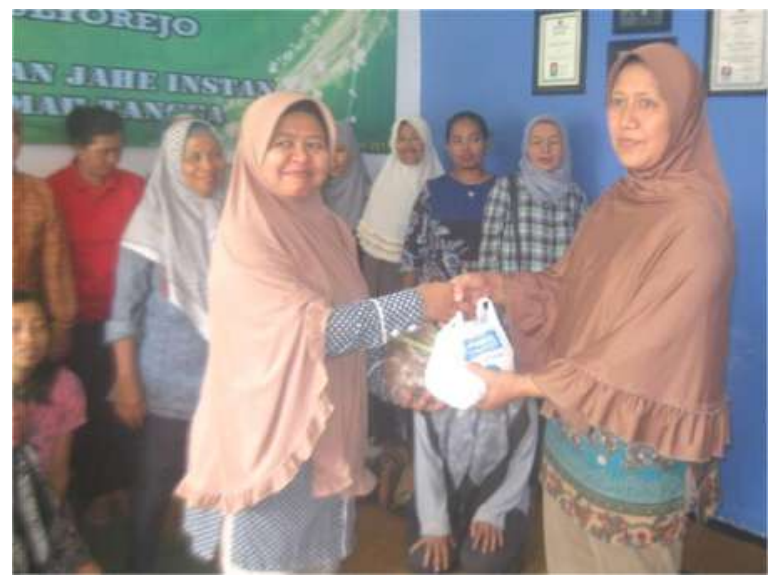

Gambar 4. Peserta latihan mendapatkan hasil jahe instan

\subsection{Pembahasan}

Pengabdian pada masyarakat ini digunakan jahe sebagai bahan baku dalam pembuatan minuman instan. Jahe dipilih karena merupakan jenis rempahrempah yang paling banyak digunakan dalam berbagai jenis makanan dan minuman. Selain itu, secara penelitian jahe memiliki berbagai macam khasiat. Pembuatan jamu jahe instan pada praktikum kali ini dilakukan dengan 2 metode yang berbeda yaitu metode konvensional dan metode instrumental, sehingga tujuan dari praktikum kali ini ialah membandingkan kedua metode tersebut. Pada metode konvensional dilakukan dengan cara pemanasan dan penambahan gula pasir. Sedangkan metode instrumental dilakukan dengan cara destilasi dan penambahan etanol untuk mendapatkan ekstrak dari jahe tersebut. Pada proses pembuatan jamu jahe instan, metode konvensional, bobot jahe yang digunakan sebanyak 250 gram. Setelah melalui proses pemasakkan bobot jahe serbuk yang dihasilkan bertambah menjadi 676,8081 gram. Bobot yang dihasilkan bertambah karena adanya penambahan gula pasir dan gula merah kedalam sari jahe. Pada proses pembuatan jamu jahe instan, metode konvensional menggunakan teknik kristalisasi. Teknik kristalisasi adalah teknik pada proses pembentukkan bahan padat dari pengendapan larutan.

Pemisahan dengan teknik kristalisasi didasari atas pelepasan pelarut dari zat terlarutnya dari sebuah campuran yang homogen sehingga terbentuk kristal dari zat terlarutnya. Teknik ini merupakan teknik alternatif yang sederhana dan murah yang dapat menghasilkan produk serbuk instan. Pada metode konvensional digunakan bahan pengkristal jahe yaitu sukrosa atau gula pasir. Secara umum mekanisme proses kristalisasi pada metode pembuatan jamu jahe instan kali ini adalah sebagai berikut sukrosa dipanaskan akan mencair dan bercampur dengan bahan lainnya, ketika air menguap membentuk kristal kembali yang terlihat sebagai butiran-butiran padat. Sifat sukrosa sangat dipengaruhi oleh $\mathrm{pH}$, jika $\mathrm{pH}$ larutan rendah (asam) maka proses kristalisasi tidak akan terbentuk dan larutan menjadi liat. Beberapa hasil penelitian menunjukkan bahwa $\mathrm{pH}$ optimum yang dapat menghasilkan produk yang baik sekitar 6,7-6,8. Selain nilai PH, suhu pemasakkan juga mempengaruhi kristalisasi. Jika suatu larutan sukrosa diuapkan maka 
konsentrasinya akan meningkat, demikian juga dengan titik didihnya. Keadaan ini akan terus berlangsung sehingga seluruh air menguap. Bila keadaan tersebut telah tercapai dan pemanasan diteruskan tanpa ada pengkontrolan suhu maka sukrosa akan melebur. Titik lebur sukrosa adalah $160^{\circ} \mathrm{C}$. Bila pemanasan melebihi suhu tersebut maka akan terjadi karamelisasi dan tidak terjadi kristalisasi, sehingga pada saat pembuatan jamu jahe instan metode konvensional yang perlu diperhatikan ialah penggunaan apinya yaitu harus api sedang. Selain itu proses pengadukkan juga sangat berpengaruh terhadap pembuatan jamu jahe instan karena proses pengadukkan harus dilakukan terus menerus karena jika pengadukan yang dilakukan merata, maka homogenitas akan tercapai dan penguapan air dalam jahe akan semakin cepat dan baik. Dalam praktikum kali ini, pembuatan atau pemprosesan jahe menjadi jahe instan/bubuk di butuhkan waktu kurang lebih 9 jam. Pembuatan jahe instan ini terbilang tidak terlalu lama. Lalu pada akhir proses pembuatan jamu jahe instan dilakukan pengayakan agar bubuk halus dan bubuk kasar terpisah.

Sedangkan pada proses pembuatan jamu jahe instan, metode instrumental, bobot jahe yang digunakan juga sebanyak 250 gram. Setelah melalui proses pemasakkan bobot jahe serbuk yang dihasilkan mengalami penyusutan menjadi 120 gram. Pada metode instrumental ini menggunakan teknik destilasi. Teknik destilasi adalah teknik pemisahan (separasi) yang berdasarkan perbedaan sifat kelarutan dari masing-masing komponen campuran terhadap jenis pelarut tertentu yang sesuai dengan komponen yang diinginkan. Hasil akhir yang diperoleh pada proses ekstraksi adalah ekstrak kental atau liquid kental yang mengandung sari / kandungan dari bahan baku tanaman tanpa adanya ampas tanaman berupa pati. Pada praktikum kali ini digunakan etanol sebagai pelarut untuk mendapatkan ekstrak sari jahe. Etanol digunakan sebagai pelarut dalam ekstraksi jamu jahe karena etanol lebih mudah menguap, bersifat polar, dan bersifat inert. Pelarut polar akan mampu menetrasi sel dan menyari semua senyawa yang terdapat dalam sel. Pelarut inert digunakan untuk menghindari terjadinya dekomposisi, misalnya reaksi metilasi, sebagaimana yang terjadi bila menggunakan pelarut metanol Sedangkan bahan pengkristal yang digunakan ialah tepung singkong yang ditambahkan dengan ekstrak jahe hasil dari proses destilasi. Pembuatan jahe menjadi jahe instan dalam metode instrumental diperlukan waktu kurang lebih 3 hari. Pembuatan jahe instan ini terbilang lama karena dibutuhkan waktu untuk merendam campuran parutan jahe dengan etanol yaitu selama 48 jam dan proses pengeringan selama 23 jam.

Pada metode ini dilakukan pengeringan menggunakan oven agar kandungan air pada bubuk jahe instan menguap sehingga kadar airnya rendah. Pada pembuatan jamu jahe instan dengan metode konvensional dan instrumental memiliki beberapa perbedaan hasil antara lain: pembuatan jamu jahe instan dengan metode konvensional menghasilkan serbuk jahe berwarna cokelat yang lebih cerah di banding jamu dengan metode instrumental. Hal ini dikarenakan pada proses pengeringan metode konvensional dilakukan dibawah sinar matahari lebih baik dibandingkan menggunakan oven pada metode instrumental Selain itu, perbedaan hasil lainnya ialah metode konvensional lebih banyak menghasilkan serbuk jahe instan di banding dengan metode instrumental. Ini di karenakan pada metode konvensional terjadi penambahan air maupun bahan pendukung yang lain seperti gula pasir maupun gula jawa sehingga dari hasil proses pemasakan lebih banyak didapatkan dari campuran tersebut.

Pelaksanaan program pengabdian kepada masyarakat yang telah dilakukan dapat dikatakan komunikatif dan cukup sukses. Nampak terlihat antara lain para peserta pelatihan merasa bertambah pengetahuan dan keterampilannya dalam bidang boga terutama dalam hal membuat jahe instan. Pengabdian pada masyarakat juga mendapat respon positif dari ibu-ibu rumah tangga atau PKK warga RT. 12 - RW. 03 Kelurahan Mulyorejo Kecamatan Sukun Kota Malang dan juga para peserta pelatihan sejak dari awal kegiatan hingga proses pelatihan ini berakhir tampak keseriusan dan kesungguhan serta keaktifan para peserta terutama pada saat mengikuti kegiatan ini. Situasi pelaksanaan praktik tampak hidup, karena kegiatan pengabdian yang melibatkan ketrampilan boga khususnya dalam hal pengolahan jahe yang belum pernah dilakukan. Oleh karena itu dirasa sebagai hal yang baru dan menarik serta peluang untuk dikembangkan. Selanjutnya terdapat harapan terjalinnya kerja sama antara pihak Politeknik Negeri Malang dan ibu-ibu PKK warga RT. 12 - RW. 03 Kelurahan Mulyorejo Kecamatan Sukun Kota Malang.

\section{PENUTUP}

\subsection{Simpulan}

Berdasarkan hasil pelaksanaan pengabdian kepada masyarakat yang telah dilakukan dapat disimpulkan sebagai berikut :

1. Setiap peserta kegiatan ini mengetahui cara memanfaatkan jahe untuk pembuatan minuman instan dan membawa hasil pelatihan dalam bentuk jahe instan.

2. Kegiatan pengabdian kepada masyarakat yang telah dilakukan ini banyak memberikan manfaat terutama menambah wawasan lebih luas dalam memahami konsep pengembangan usaha makanan terutama dalam pemanfaatan jahe dan menerapkan teori ekstraksi dan kristalisasi dalam pembuatan minuman instan.

3. Kegiatan pengabdian kepada masyarakat ini dapat dijadikan sebagai peluang baru untuk mengembangkan kewirausahaan.

\subsection{Saran}

Agar hasil minuman instan sesuai dengan yang diinginkan dan memuaskan, hendaknya menjelang terjadinya proses menjadikan kristal yaitu saat cairan mulai mengental pengadukannya sedikit dipercepat 
dan api dikecilkan, agar tidak terjadi panas yang berlebihan.

\section{DAFTAR PUSTAKA}

[1]. Nuruljanah, Tantri. Kasiat dan Kandungan Jahe Instan.

https://www.kompasiana.com/tantrinuruljanah/kha siat-dan-kandungan-jahe-instan. Diases 2 Maret 2018 pkl 08.45.

[2]. Matondang, I. 2005. Zingiber officinale L. Pusat Penelitian dan Pengembangan Tumbuhan Obat UNAS.

[3]. Hanief, Sidqa. 2013. Efektivitas Ekstrak Jahe (Zingiber officinale Roscoe) Terhadap Pertumbuhan Bakteri Streptococcus viridan. Laporan Penelitian. Universitas Islam Negeri Syarif Hidayatullah. Jakarta.

[4]. Rukmana, Rahmat. 2000. Usaha Tani Jahe. Yogyakarta: Penerbit Kanisius: 12-17.

[5]. Shukla, Y, Singh, M. 2007. Cancer preventive properties of ginger: a brief view. Journal Food Chem Toxicol. 45(5): 683-690. 